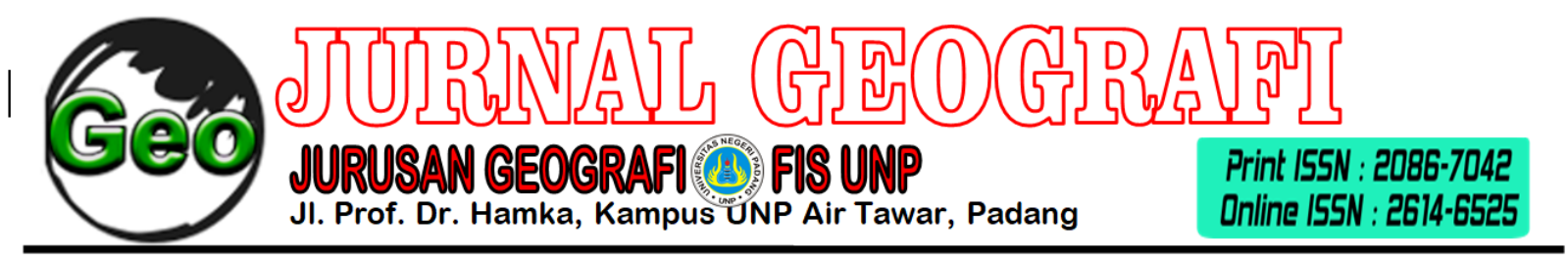

\title{
Identifikasi Sifat Kimia Tanah pada Longsor Aktif dan Longsor Inaktif (Dormant) di Desa Margoyoso Kecamatan Salaman Kabupaten Magelang Jawa Tengah
}

\author{
Dian Adhetya Arif ${ }^{1}$, Fitri Aji ${ }^{2}$, Afifu Rahman ${ }^{2}$, Ratna Wahyu Kusuma Arum ${ }^{2}$ \\ Dosen Geografi, Fakultas Ilmu Sosial, Universitas Negeri Padang ${ }^{1}$ \\ Prodi Geografi, Fakultas Ilmu Sosial, Universitas Negeri Padang ${ }^{2}$ \\ E-mail: dianadhetyaarif@gmail.com
}

\begin{abstract}
ABSTRAK
Sub DAS Bompon adalah salah satu wilayah terdampak bencana longsor yang mencakup sebagian wilayah Kabupaten Magelang, Indonesia. Sebagian Wilayah Sub DAS Bompon dimanfaatkan untuk pertanian dan permukiman, sehingga meningkatkan kerawanan penduduk terhadap longsor. Identifikasi sifat kimia tanah diperlukan sebagai dasar informasi tentang dinamika longsor. Tujuan penelitian adalah mengidentifikasi sifat kimia tanah meliputi $\mathrm{pH}$ aktual, $\mathrm{pH}$ potensial, bahan organik,dan kejenuhan basa pada longsor status aktif dan inaktif di Desa Margoyoso Kecamatan Salaman. Metode yang digunakan dalam penelitian ini adalah survei dan teknik pengambilan sampel dilakukan dengan cara stratified random sampling. Hasil identifikasi $\mathrm{pH}$ tanah menunjukkan $\mathrm{pH}$ aktual dan potensial pada dua status longsor tidak jauh berbeda berikisar antara 4,5 hingga 5,5. Kandungan Fe dan Mn banyak ditemukan pada longsor aktif dibanding pada longsor inaktif. Bahan organik banyak ditemukan di kedua status longsor dan terkonsentrasi pada morfologi tubuh dan kaki longsor. Kandungan kapur bebas (CO3) pada kedua status longsor tidak ditemukan.
\end{abstract}

Kata kunci: Longsor Aktif, Longsor Pasif, Sifat Kimia Tanah

\section{ABSTRACT}

The Bompon sub-watershed is one of the areas affected by a landslide that covers parts of Magelang Regency, Indonesia. Some of the Bompon sub-watershed areas are used for agriculture and settlements, thus increasing population vulnerability to landslides. Identification of soil chemical properties is needed as a basis for information about landslide dynamics. The aim of the study was to identify the chemical properties of soil including actual pH, potential pH, organic matter, and saturation of landslide bases of active and inactive landslide in Margoyoso Village, Salaman District. The method used in this study is a survey and the sampling technique is done by stratified random sampling. The results of the identification of soil $\mathrm{pH}$ indicate the actual and potential $\mathrm{pH}$ of two landslide statuses not much different ranging from 4.5 to 5.5. The content of $\mathrm{Fe}$ and $\mathrm{Mn}$ is found in active landslides compared to inactive landslides. Organic matters are found in both landslide type and are concentrated in main body and foot of landslides.. Free lime content (CO3) in both landslide status was not found.

Keywords: Active Landslide, Dormant Landslide, Soil Chemical Properties

\section{PENDAHULUAN}

Longsor adalah proses pergerakan massa batuan, tanah ataupun keduanya di permukaan tanah secara translasional maupun rotasional. (Highland \& Bobrowski, 2018). Longsor berdampak pada kehidupan manusia dalam berbagai hal yaitu kondisi sosial ekonomi, kerusakan lingkungan, dan korban jiwa (Eynde, Dondeyne, Isabirye, Decker, \& Poesen, 2017). Wilayah berbukit memiliki kerawanan yang tinggi terhadap longsor, termasuk Perbukitan Menoreh. Secara administratif wilayah Perbukitan Menoreh Mencakup sebagian wilayah Provinsi Jawa tengah (Kabupaten Magelang dan kabupaten Purworejo) dan Provinsi Yogyakarta (Kabupaten Kulon Progo).

Secara fisik Sub-DAS Bompon adalah bagian dari Sub-DAS Kodil yang mengalir ke Sungai Bogowonto. Secara administratif Sub-
DAS Bompon mencakup beberapa desa yaitu Desa Kwaderan Kecamatan Kajoran serta Desa Wonogiri dan Desa Margoyoso Kecamatan Salaman. Material penyusunan di DAS Bompon terdiri dari material Gunung Sumbing Muda dan Pegunungan Menoreh. Posisi DAS Bompon berada di wilayah transisi zona Jawa tengah (proses vulkanik) dan zona Jawa Bagian Selatan (zona pengangkatan). Kondisi ini mengakibatkan adanya proses endogen dan alterasi yang mengontrol Sub-DAS Bompon (Wida, Maas, \& Hadi, 2019). Secara fisik morfologi wilayah Sub-DAS Bompon adalah wilayah berbukit dan merupakan wilayah rawan kejadian longsor. Selain itu, wilayah ini juga ditinggali oleh manusia dan dimanfaatkan untuk segala aktifitasnya (Wida, Maas, \& Hadi, 2019). 
Jumlah kejadian longsor di Sub-DAS Bompon relatif banyak dan terjadi dalam beberapa tahun terakhir. Status longsor juga beragam yaitu longsor aktif dan inaktif. Kejadian longsor menyebabkan terjadinya kehilangan tanah, deposisi material sedimen, dan menghasilkan pencampuran material tanah (Eynde, Dondeyne, Isabirye, Decker, \& Poesen, 2017). Perubahan yang diakibatkan oleh longsor akan berdampak pada kualitas tanah tersebut (Błońska, Lasota, Piaszczyk, \& Wiecheć, 2017). Seringnya kejadian longsor di Sub-DAS Bompon menyebabkan perubahan morfologi dan akan berdampak juga pada kualitas tanah. oleh sebab itu, perlu dilakukan pengamatan terhadap morfologi tanah berdasarkan indentifikasi sifat kimia tanah pada longsor.

\section{METODE PENELITIAN}

Penelitian dilakukan di Sub-Das Bompon, Magelang, Jawa Tengah yaitu Desa Margoyoso Kecamatan Salaman (Gambar 1). Penelitian dilaksanakan dengan metode survei dan pengambilan sampel dilakukan dengan cara stratified random sampling yang mempertimbangkan status longsor aktif dan longsor inaktif (dormant) dengan pembeda morfologi longsor yaitu mahkota, tubuh, dan kaki longsor (Gambar 2).

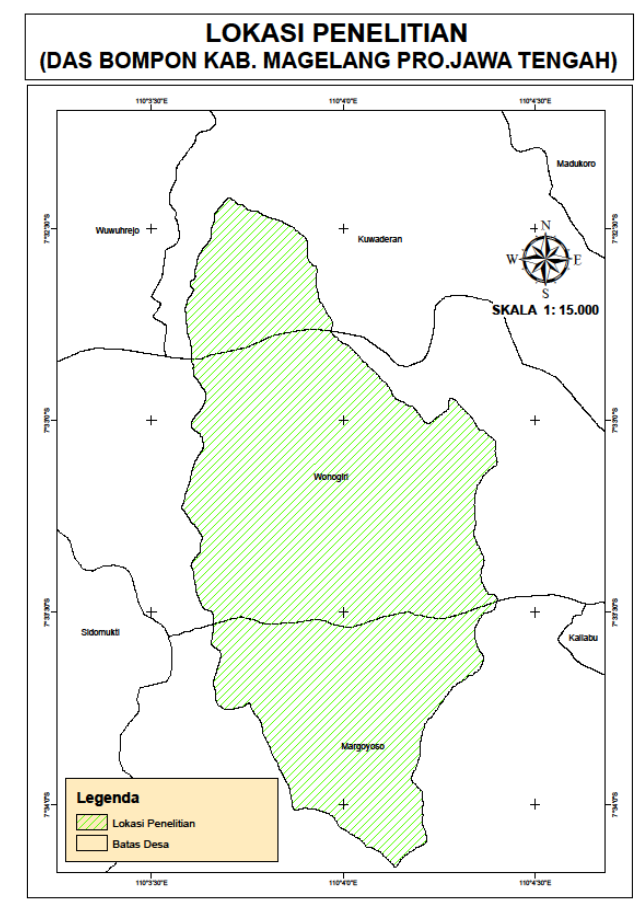

\section{Bompon.}

Identifikasi sifat morfologi tanah di lapangan meliputi identifikasi batas lapisan tanah, yang dapat diamati dari warna jika secara visual dapat dibedakan langsung antara warna lapisan satu dengan lapisan yang lain. Jika warna antara lapisan satu dengan yang lain membaur maka dapat dibedakan berdasarkan tekstur. Identifikasi sifat kimia tanah di lapangan meliputi identifikasi $\mathrm{pH}$ tanah, bahan organik, $\mathrm{Fe}$ dan $\mathrm{Mn}$, dan drainase. $\mathrm{pH}$ tanah diidentifikasi dengan dua cara yaitu menghitung $\mathrm{pH}$ aktual menggunakan cairan $\mathrm{H}_{2} \mathrm{O}$ dan $\mathrm{pH}$ potensial menggunakan $\mathrm{KCl}_{1} \mathrm{~N}$. selanjutnya bahan organik diidentifikasi menggunakan larutan $\mathrm{H}_{2} \mathrm{O}_{2}$ 10\%. Begitu pula untuk melihat kandungan $\mathrm{Fe}$ dan $\mathrm{Mn}$ dapat diketahui dengan meneteskan lautan $\mathrm{H}_{2} \mathrm{O}_{2} 3 \%$ pada segumpal sampel tanah. Drainase tanah dapat diidentifikasi dengan meneteskan larutan $\alpha \alpha$ bipiridin.

\section{HASIL DAN PEMBAHASAN}

DAS Bompon memiliki morfologi berupa perbukitan, ketebalan tanah lebih dari 4 meter, rendah bahan organik, material penyusun dasar dan permukaan berupa klei dan terdapat material alterasi hasil dari proses intrusi. Kenampakan fisik Sub-DAS Bompon dipengaruhi oleh aktifitas manusia berupa pembukaan lahan pertanian seperti kebun campuran dan tanaman musiman di punggungan bukit, serta pemotongan lereng untuk jalan dan rumah. Aktifitas manusia berupa pembukaan lahan pertanian dan pemotongan lereng menyebabkan lereng tidak stabil, sehingga mempengaruhi intensitas terjadinya tanah longsor.

Gambar 1. Peta Lokasi Penelitian DAS 


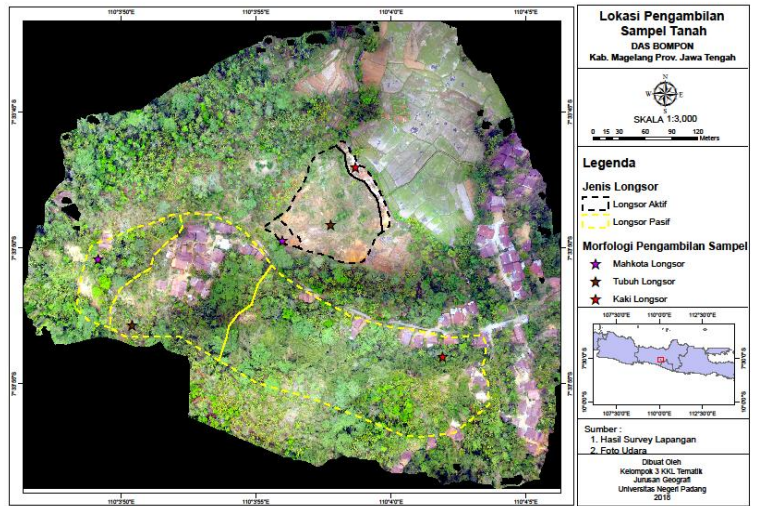

Gambar 2. Peta lokasi pengambilan sampel tanah DAS Bompon.

\section{Karakteristik Medan Longsor}

Tipe longsor aktif di lokasi penelitian (Gambar 3) merupakan tipe longsor rotasional yang disebabkan oleh bentuk bidang gelincir yang cekung. Tipe longsor rotasional juga dapat dikenali melalui morfologi permukaan longsor, yakni dicirikan dengan bentuk endapan yang menyerupai tangga berundak. Kejadian longsor tipe rotasional ini terjadi pada wilayah perbukitan dengan kecepatan pergerakan material longsor dapat terjadi secara pelan hingga sangat cepat.

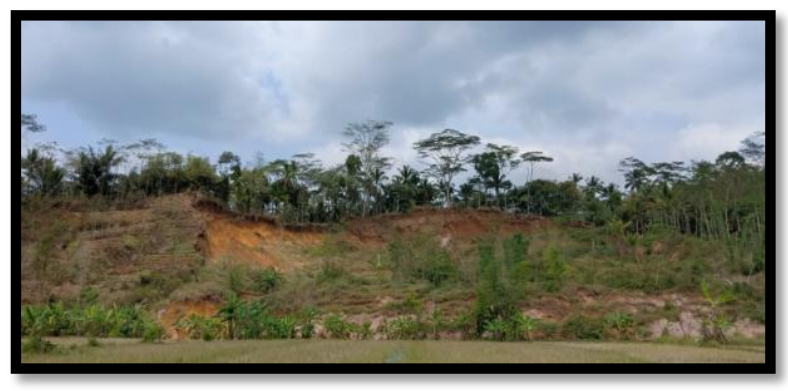

Gambar 3. kenampakan salah satu longsor aktif

Tabel 1. Morfologi longsor aktif.

\begin{tabular}{llllll}
\hline $\begin{array}{l}\text { Morfo } \\
\text { logi }\end{array}$ & Makro & Mikro & $\begin{array}{l}\text { Elevas } \\
\text { i Mdpl } \\
\text { ) }\end{array}$ & $\begin{array}{l}\text { Pengg } \\
\text { unaan } \\
\text { lahan }\end{array}$ & $\begin{array}{l}\text { Jenis } \\
\text { Tanam } \\
\text { an }\end{array}$ \\
\hline $\begin{array}{l}\text { Mahk } \\
\text { ota }\end{array}$ & Cekung & $\begin{array}{l}\text { Beralu } \\
\text { r }\end{array}$ & 477 & $\begin{array}{l}\text { Campu } \\
\text { ran }\end{array}$ & $\begin{array}{l}\text { Bambu, } \\
\text { kelapa, } \\
\text { sengon, } \\
\text { dan } \\
\text { semak }\end{array}$ \\
\hline & & & & & $\begin{array}{l}\text { Pisang, } \\
\text { ilalang, } \\
\text { kelapa, } \\
\text { petai } \\
\text { dan } \\
\text { kubuhyit. }\end{array}$ \\
\hline
\end{tabular}

\begin{tabular}{cccl}
\hline Kaki Cekung Gilgai 444 & $\begin{array}{l}\text { Campu } \\
\text { ran }\end{array}$ & $\begin{array}{l}\text { Pisang, } \\
\text { ilalang, } \\
\text { bambu, } \\
\text { dan } \\
\text { kelapa }\end{array}$ \\
\hline
\end{tabular}

Sumber :Observasi lapangan

Tabel 1 menunjukkan informasi morfologi, penggunaan lahan dan jenis tanaman pada masing-masing morfologi longsor aktif di lokasi penelitian. seluruh bagian longsor tersebut dijadikan titik sampel dalam mengamati keadaan medan longsor aktif. Umumnya kemas muka tanah pada tiga titik sampel terlihat adanya retak-retakan pada tanah. Timbulan makro pada seluruh titik sampel longsor aktif berbentuk cekung. Timbulan mikro longsor aktif bagian mahkota berbentuk beralur, sedangkan bagian tubuh dan kaki longsor berbentuk gilgai.

Penggunaan lahan pada bagian mahkota longsor aktif yaitu kebun campuran dengan vegetasi yang tumbuh di atasnya antara lain bambu, kelapa, sengon, ilalang, petai, kunyit, dan semak. Sebagian besar tanaman adalah tanaman budidaya, yang mengindikasikan bahwa pemanfaatan longsor aktif cukup intens. Hal ini terjadi karena lahan yang dibudidayakan sebagai salah satu harta benda dan aktivitas untuk pemenuhan kebutuhan ekonomi penduduk setempat.

Proses erosi juga berpengaruh besar terhadap longsor aktif. Jenis erosi yang terjadi yaitu erosi parit pada morfologi tubuh longsor, sedangkan bagian kaki terjadi pengikisan tanah lapisan atas. Selain itu, terjadi pula pemadatan permukaan tanah sehingga laju infiltrasi menurun dan meningkatkan volume aliran permukaan. Pada lahan terbuka tanpa tanaman dengan tingkat kecuraman lereng tertentu, kecepatan aliran permukaan yang terjadi ketika turun hujan dapat menyebabkan erosi. Proses ini akan berdampak pada penurunan kesuburan tanah yang disebabkan oleh hilangnya kandungan organik pada bagian permukaan tanah (Eynde, Dondeyne, Isabirye, Decker, \& Poesen, 2017).

\section{Karakteristik medan longsor Inaktif (dormant)}

Lokasi tanah longsor inaktif (dormant) di Desa Margoyoso masih mengalami 
pergerakan dan belum mencapai titik stabil. Ketidakstabilan tersebut disebabkan oleh gerusan air sungai yang pada morfologi kaki longsor (toe) sehingga material yang diatasnya akan bergerak ke bawah secara alami. Singkapan tanah longsor inaktif (dormant) juga menunjukkan bahwa solum tanah di bagian lereng mahkota dapat dikatakan tebal. Ketebalan tanah tersebut merupakan salah satu syarat terjadinya tanah longsor, yakni adanya material tanah yang dilongsorkan.

Tanah tersebut juga memiliki warna yang berbeda pada setiap lapisannya. Setelah diidentifikasi menggunakan buku Munsell Soil Color Chart diketahui bahwa lapisan pertama berwarna reddish yellow (kuning kemerahan), lapisan kedua berwarna Dark Yellowish Brown (coklat gelap kekuningan), lapisan ketiga berwarna Yellowis Brown (coklat kekuning-kuningan) dan lapisan ke empat berwarna Red (merah). Warna tanah menunjukkan komposisi mineral, kandungan air dan organik. Tanah cenderung merah jika terdapat kandungan besi, dan cenderung gelap jika kandungan organik tinggi (Owens \& Rutledge, 2005).

\section{Identifikasi Sifat Kimia Tanah Longsor Aktif}

\section{Mahkota Longsor}

Informasi mengenai karakteristik kimia tanah pada bagian mahkota longsor aktif disajikan pada tabel 2.

Tabel 2. Karakteristik Kimia Mahkota Longsor Aktif

\begin{tabular}{|c|c|c|c|c|c|c|}
\hline \multirow{2}{*}{$\begin{array}{c}\text { Titik } \\
\text { Samp } \\
\text { el }\end{array}$} & \multirow{2}{*}{$\begin{array}{c}\text { Lapis } \\
\text { an }\end{array}$} & \multicolumn{2}{|c|}{ PH } & \multirow{2}{*}{$\begin{array}{c}\mathbf{F e} \\
\mathbf{M} \\
\mathbf{n}\end{array}$} & \multirow{2}{*}{$\begin{array}{c}\text { Bahan } \\
\text { Organ } \\
\quad \text { ik }\end{array}$} & \multirow{2}{*}{$\begin{array}{c}\text { CO3 } \\
\text { Beb } \\
\text { as }\end{array}$} \\
\hline & & $\begin{array}{l}\text { Aktu } \\
\text { al }\end{array}$ & $\begin{array}{l}\text { Potensi } \\
\text { al }\end{array}$ & & & \\
\hline \multirow{2}{*}{$\begin{array}{c}\text { Mahko } \\
\text { ta }\end{array}$} & 2 & 5 & 5 & - & Sedikit & - \\
\hline & 4 & 5 & 5.5 & 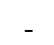 & & - \\
\hline
\end{tabular}

Sumber: data primer 2018

Di bagian morfologi mahkota longsor terdapat 4 lapisan tanah. Sampel $\mathrm{pH}$ aktual dan potensial diambil dari lapisan tanah yang memiliki karakteristik yang hampir sama dilihat dari warnanya yaitu lapisan 2 dan 4 . Lapisan tanah 2 dan 4 masing-masing memiliki nilai pH 5 dan 5,5. Di bagian mahkota ini, tanah tidak memiliki kandungan besi ( $\mathrm{Fe}$ dan $\mathrm{Mn}$ ). Bahan organik yang dimiliki pada bagian mahkota terdapat pada lapisan 2, namun hanya sedikit bahan organik yang dimiliki pada lapisan ini. Pengamatan terhadap kapur bebas (CO3) pada bagian mahkota juga dilakukan, namun tidak ditemukan indikasi keterdapatan kapur bebas. Kondisi pH menunjukkan bahwa tanah bersifat asam. Sifat tanah yang demikian berpengaruh pada proses degradasi material organik yang diperlukan tanaman (A. \& N., 2013). Proses yang terganggu akan berdampak pada produksi tanaman yang tidak toleran terhadap tanah asam (Grattan \& Läuchl, 2012).

\section{Tubuh Longsor}

Informasi mengenai karakteristik kimia tanah pada bagian tubuh longsor aktif disajikan pada tabel 3.

Tabel 3. Karakteristik Kimia Tubuh Longsor Aktif

\begin{tabular}{|c|c|c|c|c|c|c|}
\hline \multirow{2}{*}{$\begin{array}{c}\text { Titik } \\
\text { samp } \\
\text { el }\end{array}$} & \multirow{2}{*}{$\begin{array}{c}\text { Lapis } \\
\text { an }\end{array}$} & \multicolumn{2}{|c|}{ PH } & \multirow{2}{*}{$\begin{array}{c}\text { Fe } \\
\text { Mn }\end{array}$} & \multirow{2}{*}{$\begin{array}{c}\text { Baha } \\
\text { n } \\
\text { Orga } \\
\text { nik }\end{array}$} & \multirow{2}{*}{$\begin{array}{c}\text { CO } \\
3 \\
\text { Beb } \\
\text { as }\end{array}$} \\
\hline & & $\begin{array}{c}\text { Aktu } \\
\text { al }\end{array}$ & $\begin{array}{c}\text { Potens } \\
\text { ial }\end{array}$ & & & \\
\hline \multirow{3}{*}{$\begin{array}{c}\text { Tubu } \\
\mathrm{h}\end{array}$} & 1 & 4.5 & 5 & - & $\begin{array}{c}\text { Banya } \\
\mathrm{k}\end{array}$ & - \\
\hline & 2 & & & - & $\begin{array}{c}\text { Banya } \\
\mathrm{k}\end{array}$ & - \\
\hline & 3 & & & $\begin{array}{c}\text { sedi } \\
\text { kit }\end{array}$ & $\begin{array}{c}\text { Banya } \\
k\end{array}$ & - \\
\hline
\end{tabular}

Sumber: data primer 2018

Di bagian morfologi ubuh longsor terdapat 3 lapisan tanah. $\mathrm{pH}$ aktual dan potensial tanah diperoleh dari sampel yang mewakili warna tanah yang hampir sama yaitu lapisan 1. Nilai $\mathrm{pH}$ aktual dan $\mathrm{pH}$ potensial yang diperoleh masing-masing adalah 4.5 dan 5. Di bagian morfologi tubuh longsor aktif, tanah tidak memiliki kandungan besi pada lapisan 1 dan 2, sedangkan lapisan 3 hanya terdapat sedikit kandungan besi dan mangan. Pengujian terhadap bahan organik tanah menunjukkan bahwa bahan organik terdapat pada semua lapisan sampel tanah, dan pengujian kapur bebas (CO3) menunjukkan bahwa di bagian ini tidak terdapat kandungan kapur. 


\section{Kaki Longsor}

Informasi mengenai karakteristik kimia tanah pada bagian kaki longsor aktif disajikan pada tabel 4 .

Tabel 4. Karakteristik Kimia Kaki Longsor Aktif

\begin{tabular}{cccccc}
\hline \multirow{2}{*}{$\begin{array}{c}\text { Titik } \\
\text { sampel }\end{array}$} & Lapisan & \multicolumn{2}{c}{ PH } & $\begin{array}{c}\text { Bahan } \\
\text { Organik }\end{array}$ \\
\cline { 2 - 5 } Kaki & & \multicolumn{2}{c}{ Aktual } & Potensial & \\
\cline { 2 - 5 } & 2 & 4.5 & 4.5 & Sedikit & sedikit \\
\cline { 2 - 5 } & 3 & & sedikit & Sedikit \\
\hline
\end{tabular}

Sumber: data primer 2018

Identifikasi sifat kimia tanah di lapangan meliputi identifikasi $\mathrm{pH}$ tanah, bahan organik, Fe dn Mn, kadar kapur bebas dan drainase. Di bagian kaki longsor terdapat 3 lapisan tanah. $\mathrm{pH}$ aktual dan potensial tanah diperoleh dari sampel yang mewakili warna tanah yang hampir sama yaitu lapisan 1. Nilai pH aktual dan $\mathrm{pH}$ potensial yang diperoleh masingmasing adalah 4.5 dan 4,5. Ini menunjukkan bahwa tanah bersifat asam. Hasil pengujian sampel menunjukkan bahwa terdapat sedikit Fe dan Mn pada seluruh lapisan tanah. Bahan organik pada setiap lapisan sedikit dan pengujian kapur bebas (CO3) pada bagian menunjukkan bahwa tidak terdapat kapur.

\section{Identifikasi Sifat Kimia Tanah Longsor Inaktif (Dormant)}

\section{Mahkota Longsor}

Informasi mengenai karakteristik kimia tanah pada bagian mahkota longsor inaktif disajikan pada tabel 5 .

Tabel 5. Karakteristik Kimia Mahkota

\begin{tabular}{|c|c|c|c|c|c|c|}
\hline \multirow{3}{*}{$\begin{array}{c}\text { Titik } \\
\text { Samp } \\
\text { el } \\
\end{array}$} & \multicolumn{6}{|c|}{ Longsor inaktif } \\
\hline & & & $\mathrm{H}$ & & Bahan & $\mathrm{CO3}$ \\
\hline & Еаро & $\begin{array}{l}\text { Aktu } \\
\text { al }\end{array}$ & $\begin{array}{l}\text { Potens } \\
\text { ial }\end{array}$ & $\begin{array}{c}\mathbf{M} \\
\mathbf{n}\end{array}$ & $\begin{array}{c}\text { Organ } \\
\text { ik }\end{array}$ & $\begin{array}{c}\text { Beb } \\
\text { as } \\
\end{array}$ \\
\hline \multirow{2}{*}{$\begin{array}{c}\text { Mahk } \\
\text { ota }\end{array}$} & 2 & 5 & 5 & - & Sedikit & - \\
\hline & 4 & 5.5 & 5.5 & - & Sedikit & - \\
\hline
\end{tabular}

Sumber: data primer 2018

Di bagian mahkota pada longsor inaktif terdapat 4 lapisan tanah. $\mathrm{pH}$ aktual dan potensial tanah diperoleh dari sampel yang mewakili warna tanah yang hampir sama yaitu lapisan 2 dan 4. Nilai $\mathrm{pH}$ aktual potensial yang diperoleh masing-masing sampel adalah 5 dan 5.5, sedangkan Nilai $\mathrm{pH}$ potensial yang diperoleh masing-masing adalah 5 dan 5.5. di bagian ini tidak terdapat Fe Mn. Kandungan bahan organik paling banyak ditemukan di lapisan 1 sedangkan lapisan 2 dan 3 hanya sedikit bahan organik Co3erta kapur bebas (CO3) di bagian mahkota tidak ditemukan.

\section{Tubuh longsor}

- Informasi mengenai karakteristik kimia tanah pada bagian tubuh longsor inaktif disajikan pada tabel 6 .

Tabel 6. Karakteristik Kimia Tubuh Longsor inaktif

\begin{tabular}{|c|c|c|c|c|c|c|}
\hline \multirow{2}{*}{$\begin{array}{c}\text { Titik } \\
\text { Samp } \\
\text { el }\end{array}$} & \multirow[b]{2}{*}{$\begin{array}{c}\text { Lapis } \\
\text { an }\end{array}$} & \multicolumn{2}{|c|}{ PH } & \multirow{2}{*}{$\begin{array}{c}\mathbf{F e} \\
\mathbf{M} \\
\mathbf{n}\end{array}$} & \multirow{2}{*}{$\begin{array}{c}\text { Bahan } \\
\text { Organ } \\
\text { ik }\end{array}$} & \multirow{2}{*}{$\begin{array}{c}\text { CO3 } \\
\text { Beb } \\
\text { as }\end{array}$} \\
\hline & & $\begin{array}{l}\text { Aktu } \\
\text { al }\end{array}$ & $\begin{array}{l}\text { Potensi } \\
\text { al }\end{array}$ & & & \\
\hline Mahko & 2 & 5.5 & 5 & - & - & - \\
\hline ta & 4 & 5 & 4.5 & - & - & - \\
\hline
\end{tabular}

Sumber: data primer 2018

Di bagian tubuh longsor inaktif, diidentifikasi 4 lapisan tanah. 2 sampel tanah diambil dengan mempertimbangkan kesamaan warna tanah yaiut lapisan 2 dan 4 . Nilai pH aktual yang diperoleh masingmasing adalah 5 dan 5.5, sedangkan Nilai $\mathrm{pH}$ potensial yang diperoleh masing-masing adalah 5 dan 5.5. Di bagian tubuh ini, tanah diindikasikan tidak memiliki kandungan besi (Fe dan $\mathrm{Mn}$ ), tidak memiliki bahan oganik dan tidak terdapat $\mathrm{CO} 3$ bebas.

\section{Kaki Longsor}

Informasi mengenai karakteristik kimia tanah pada bagian kaki longsor inaktif disajikan pada tabel 7 .

Tabel 7. Karakteristik Kimia kaki Longsor inaktif

\begin{tabular}{|c|c|c|c|c|c|c|}
\hline \multirow{2}{*}{$\begin{array}{c}\text { Titik } \\
\text { Sam } \\
\text { pel }\end{array}$} & \multirow[b]{2}{*}{$\begin{array}{c}\text { Lapi } \\
\text { san }\end{array}$} & \multicolumn{2}{|c|}{ PH } & \multirow[b]{2}{*}{$\begin{array}{c}\mathrm{Fe} \\
\mathrm{Mn}\end{array}$} & \multirow{2}{*}{$\begin{array}{l}\text { Bahan } \\
\text { Organi } \\
\text { k }\end{array}$} & \multirow{2}{*}{$\begin{array}{c}\text { CO3 } \\
\text { Bebas }\end{array}$} \\
\hline & & $\begin{array}{c}\text { Aktua } \\
\text { l }\end{array}$ & $\begin{array}{c}\text { Potens } \\
\text { ial }\end{array}$ & & & \\
\hline \multirow{3}{*}{ Kaki } & 1 & & & - & Banyak & - \\
\hline & 2 & 5 & 5.5 & $\begin{array}{l}\text { Sedik } \\
\text { it }\end{array}$ & Banyak & - \\
\hline & 3 & & & - & Banyak & - \\
\hline
\end{tabular}

Sumber: data primer 2018 
Identifikasi sifat kimia tanah di lapangan meliputi identifikasi $\mathrm{pH}$ tanah, bahan organik, Fe dn Mn, kadar kapur bebas dan drainase. Dibagian kaki longsor terdapat 3 lapisan tanah. Seluruh sampel lapisan tanah memiliki karakteristik yang hampir sama dari segi warna sehingga pengujian dilakukan hanya pada satu lapisan tanah yaitu lapisan 2 . Sampel tanah memiliki nilai $\mathrm{pH}$ aktual 5 dan $\mathrm{pH}$ potensial 5,5. Kandungan $\mathrm{Fe}$ dan $\mathrm{Mn}$ di lapisan 2 hanya sedikit namundi setiap lapisan memiliki banyak kandungan bahan organik, sementara untuk CO3 Bebas pada setiap lapisan tidak ditemukan.

\section{SIMPULAN}

Secara umum kondisi fisik Sub-DAS Bompon memiliki timbulan makro yang cekung. Pengujian $\mathrm{pH}$ tanah menunjukkan kesamaan sifat tanah yaitu asam. Bahan organik yang dimiliki di sebagian besar sampel mahkota dan tubuh longsor pada masing-masing status longsor hanya sedikit, hal ini terjadi karena bahan organik mulai hilang ketika terjadinya erosi. Sebaliknya, di bagian kaki longsor ditemukan kandungan organik cukup banyak yang disebabkan oleh penumpukkan hasil erosi bagian mahkota dan tubuh longsor ini ada pada kaki longsor.

\section{DAFTAR RUJUKAN}

A., N. I., \& N., N. L. (2013). Soil PH An Indices For Effective Management Of Soils For Crop Production. International Journal of Scientific \& Technology Research, 132-134.

Błońska, E., Lasota, J., Piaszczyk, W., \& Wiecheć, M. (2017). The Effect Of Landslide On Soil Organic Carbon Stock And Biochemical Properties Of Soil. Journals Soil Sediments.

Eynde, E. V., Dondeyne, S., Isabirye, M., Decker, J., \& Poesen, J. (2017). Impact Of Landslides On Soil Characteristics: Implications For Estimating Their Age. Catena, 179-179.

Grattan, S., \& Läuchl, A. (2012). Soil pH Extremes. Plant Stress Physiology, 194-209.

Highland, L., \& Bobrowski, P. (2018). Landslide Types: Descriptions, Illustrations, and Photos. In K. Sassa, F. Guzzeti, H. Yamagishi, Z. Arbanas, N. Casagli, \& M. McSaveney, Landslide Dynamics, ISDR-ICL Landslide Interactive Teaching Tools (pp. 1-38). Cham, Switzerland: Springer Nature.

Owens, P. R., \& Rutledge, E. M. (2005). Morphology. Encyclopedia of Soils in the Environment, 511-520.

Wida, W. A., Maas, A., \& Hadi, J. S. (2019). Pedogenesis of Mt. Sumbing Volcanic Ash Above the Alteration Clay Layer in the Formation of Landslide Susceptible Soils in Bompon SubWatershed. Agricultural Science, 15-22. 